\title{
INVESTIGACIONES
}

\section{Obstáculos y necesidades en la trayectoria formativa y profesional del profesor mentor principiante}

\author{
Obstacles and needs in the formative and professional trajectory \\ of the beginner teacher mentor
}

\section{Sandra González-Miguel ${ }^{a}$, Cristina Mayor Ruiz ${ }^{b}$ Elena Hernández de la Torrec}

\author{
${ }^{a}$ Doctoranda. Facultad Ciencias de la Educación. Universidad de Sevilla. \\ sangonmig@hotmail.com \\ ${ }^{b}$ Catedrática de Universidad. Departamento de Didáctica y Organización Educativa (DOE). \\ Facultad Ciencias de la Educación. Universidad de Sevilla. \\ crismayr@us.es \\ ${ }^{c}$ Profesora Titular de Universidad. Departamento de Didáctica y Organización Educativa (DOE). \\ Facultad Ciencias de la Educación. Universidad de Sevilla. \\ eht@us.es
}

\section{RESUMEN}

Los cambios actuales en educación necesitan nuevos agentes que faciliten el desarrollo profesional de los docentes para contribuir a la mejora del desempeño laboral. Los programas de iniciación a la práctica profesional constituyen el puente hacia la mejora educativa con especial atención a figuras claves como la del mentor. Este estudio se centra en conocer y analizar los obstáculos y necesidades formativas/profesionales del profesor mentor principiante, rol inmerso en un Programa para la Iniciación a la Práctica Profesional en República Dominicana. La metodología es cualitativa atendiendo a los instrumentos: guías de autopresentación, biogramas e incidentes críticos a un total de 10 participantes. Los resultados y discusión muestran que los mentores principiantes poseen carencias formativas tecno-pedagógicas que dificultan su propia práctica profesional necesitando ayuda institucionalizada y mayor espacio temporal para la capacitación en mentoría. Ante ello, concluimos que el mentor cuenta con actitud positiva ante las mejoras educativas de su país.

Palabras claves: mentoría, desarrollo profesional, asesoramiento, formación de docentes, práctica pedagógica.

\begin{abstract}
The current changes in education need new agents that facilitate the professional development of teachers to contribute to the improvement of work performance. The initiation programs to the professional practice constitute the bridge towards educational improvement with special attention to key figures such as the mentor. This study focuses on knowing and analyzing the obstacles and training/professional needs of the beginning mentor teacher, role immersed in a Program for Initiation to Professional Practice in the Dominican Republic. The methodology is qualitative according to the instruments: self-presentation guides, biograms and critical incidents for a total of 10 participants. The results and discussion show that beginning mentors have techno-pedagogical training deficiencies that hinder their own professional practice, needing institutionalized help and more time for mentoring training. Given this, we conclude that the mentor has a positive attitude towards the educational improvements in his country.
\end{abstract}

Key words: mentoring, professional development, counseling, teacher training, pedagogical practice. 


\section{INTRODUCCIÓN}

La Secretaría de Estado de Educación determina que los continuos cambios socioeconómicos, culturales y educativos actuales muestran una necesidad de mejora en la formación profesional docente (SEE, 2009). Concretamente, este estudio aborda la figura del profesor mentor principiante, enclavada en un Programa de Inducción Profesional a la Docencia denominado INDUCTIO, en República Dominicana. Las políticas educativas de este país adolecen dos problemas básicos: insuficiente motivación en el desempeño profesional docente y las inadecuadas condiciones laborales para su desarrollo profesional (estructura educativa, remuneración e incentivos). Estas dificultades son la base para el dilema de la elección de la profesión de maestro como primera carrera profesional (Vaillant, 2007). Esto acarrea un problema principal a resolver en la mayoría de los países latinoamericanos ya que presentan serias dificultades a la hora de contratar profesorado principiante con un buen nivel de formación. La respuesta a este problema conllevaría un aumento y garantía de la calidad de la enseñanza en todos los niveles (Beca, 2012).

En República Dominicana la formación inicial docente se lleva a cabo en la "Universidad Autónoma de Santo Domingo" (UASD) y en el organismo estatal "Instituto Superior de Formación Docente Salomé Ureña" (ISFODOSU) sin existir Programas de Iniciación Profesional a la Docencia que contribuyan a la mejora de la formación (teórica y práctica) del profesorado. La finalidad de dichos programas es la de obtener un buen desempeño docente y estimular a los docentes principiantes para la dedicación plena al puesto laboral. Por lo que en clave de mejora surge la figura del profesor mentor principiante como guía y apoyo continuo en el inicio profesional docente evitando posibles situaciones de abandono profesional (Beca, 2012). Ante tal situación, entendemos que el acompañamiento y asesoramiento ofrecido por el profesor mentor principiante debe tener calidad formativa al convertirse en un agente de vital importancia para el éxito del proceso de iniciación a la práctica profesional de profesores noveles.

En la mayoría de los países latinoamericanos, los sistemas educativos cuentan con problemas de índole formativa ante el personal laboral. En el caso de República Dominicana, los profesores mentores principiantes inmersos en Proyectos de Iniciación a la Práctica Profesional Docente deben estar formados en una serie de competencias específicas en su rol para garantizar una calidad en los procesos de asesoramiento a los docentes principiantes (Beca, 2012). Por lo que los autores, Martín-Romera y GarcíaMartínez (2018) coinciden que para realizar una "re-definición constante del perfil del mentor se requiere del desarrollo de enfoques de indagación más comprensivos y ligados al quehacer docente que permitan reflexionar sobre la práctica y construir conocimiento práctico que sea trasladado a la formación" (p. 10).

Por esto, para llegar a ser mentor, es necesario tener en cuenta antecedentes formativos y profesionales con criterios específicos para la selección al Programa de Iniciación a la Práctica Profesional entre los que se encuentran: ser docente con siete o más años de experiencia en el aula, coordinador pedagógico o participante en Proyectos de Innovación Docente, participantes en actividades de mejora escolar y actividades de formación docente como formador. A su vez, uno de los requisitos indispensables para incorporarse al Programa es la dedicación a tiempo completo para desarrollar una buena labor.

En definitiva, el problema principal de investigación que presentamos versa sobre la figura del profesor mentor principiante como sujeto experto en el ámbito educativo 
que necesita de formación permanente en materia de asesoramiento, liberación de otros roles laborales simultáneos, apoyo económico y futura creación oficial de este desempeño laboral. De este modo proponemos una serie de cuestiones de investigación a resolver a lo largo del artículo como son:

a) ¿Cuáles son los antecedentes formativos y laborales del profesor mentor principiante?

b) ¿Qué necesidades profesionales encuentra el profesor mentor principiante en la práctica?

c) ¿Qué obstáculos encuentran en sus trayectorias profesionales y formativas para desempeñar el rol de mentor?

Atendiendo a estas interrogaciones, la teoría que mostramos está inmersa en el Desarrollo Profesional Docente bajo el rol de mentor principiante, definiendo ambos conceptos y la definición del término de conocimiento profesional íntimamente relacionado con la citada figura, continuando con las etapas por las que transcurre y las competencias del profesor mentor principiante.

\section{DESARROLLO PROFESIONAL DOCENTE EN LA FIGURA DEL MENTOR PRINCIPIANTE}

Ante la aproximación conceptual al Desarrollo Profesional Docente (en adelante DPD) nos detenemos en Montecinos (2003) definiéndolo como "variedad de instancias formales e informales que ayudan a un profesor a aprender nuevas prácticas pedagógicas, junto con desarrollar una nueva comprensión acerca de su profesión, su práctica y el contexto en el cual se desempeña" (p. 108). Es decir, el avance del DPD está supeditado al cúmulo de experiencias ligadas a la teoría aprendida en los estudios superiores. Vaillant y CardozoGaibisso (2016) añaden que el concepto concierne a la mejora de las buenas prácticas en mentoría y como resultado de ello existe un avance en la figura de los docentes principiantes en su labor profesional. La propia autora Vaillant (2016) defiende que "puede producirse de forma relativamente autónoma y personal en un espacio intersubjetivo y social" (p. 8). Sin embargo, la Organización para la Cooperación y el Desarrollo Económico (OECD, 2017), considera que no puede ser un proceso aislado, sino que para que el DPD cuente con una elevada rigurosidad debe "brindar oportunidades para aplicar métodos de aprendizaje activos, durante un periodo de tiempo prolongado, participando en grupos de colegas y actividades de aprendizaje colectivo" (p. 1).

Para atender a la definición de profesor mentor principiante primero definimos la mentoría siguiendo a los autores Fogarty, Reinstein, Heath y Sinason (2017) como una "relación diádica (dos personas), donde una persona mayor, más experimentada (llamada mentor) proporciona consejo, consejo u orientación a una persona menor, menos experimentada (llamada protegido)" (p. 63). Por lo que entendemos que el profesor mentor es definido como personal docente con experiencia, reconocido prestigio por su calidad docente e intervención en proyectos de innovación educativa. Los mentores evolucionan desde la fase de profesores principiantes en sus inicios laborales, a profesores expertos, al igual que han pasado de ser mentores principiantes a ser posteriormente mentores expertos. Teniendo en cuenta estas definiciones, nos basamos en la defendida por Gunuc y Kuzu (2015) ya que detallan que el rol del mentor se puede concretar como "la persona que guía 
en el proceso de inducción profesional al docente novel" (p. 167). En otras palabras, la figura del mentor se define como aquel que suministra ayuda, asesoramiento, orientación, recursos, etc.; y el docente principiante es el que recibe todo lo citado. Los autores Núñez, Pino y López (2011) defienden la mentoría como una "modalidad de orientación para el docente que recién inicia su ejercicio profesional, a través del trabajo conjunto con un profesor con más experiencia" (p. 1150).

Uno de los rasgos determinantes del profesor mentor principiante son las experiencias profesionales y su camino anterior formativo por lo que vamos a definir el término de conocimiento profesional, el que se va forjando en el transcurso de los años profesionales. En palabras de Martínez y Valbuena (2013) es “conocimiento diferenciado epistemológicamente, el cual posee un carácter práctico y se construye a partir de la integración y transformación de distintos saberes, conocimientos y concepciones de diversas fuentes" (p. 118). En este sentido, el conocimiento profesional es un proceso llevado a cabo por los docentes en el que recopilan su propia experiencia acompañada de saberes, conocimientos y concepciones. De igual modo, Gewerc y Montero (2015) señalan que "el conocimiento profesional es la base de la competencia profesional del profesorado (...) implica conocimientos y se comprueba en la acción, en la capacidad de responder a demandas complejas y llevar a cabo tareas diversas de forma adecuada" (p. 34). Nuñez (2019) defiende que "el conocimiento práctico profesional docente es experiencial y se construye de manera situada en los contextos" (p. 218). Sin embargo, Abrahão y Bolívar (2014) determinan que la clave del conocimiento profesional no solo está en la experiencia, sino en el estudio del desarrollo profesional propio de los profesores mentores principiantes y la cultura profesional en la que están inmersos, construyéndose desde la base formativa y consolidándose con el paso de los años en el que influyen todos los ámbitos: familiar, laboral, experiencial, teórico, práctico, etc. En este punto no olvidemos que para todo esto necesitan una estabilidad particular en la adquisición del conocimiento profesional y un equilibrio personal.

Entrando en la materia de las etapas del DPD, Marchesi (2007), lo divide en seis grandes periodos: "formación inicial, iniciación, estabilización, nuevas preocupaciones, alejamiento o responsabilidad y declive profesional cuando se aproxima la edad de jubilación" (p. 42); sin embargo, Vaillant (2016) prefiere acotar las etapas en cuatro, tal como mostramos en la Figura 1:

Figura 1. Etapas del desarrollo profesional

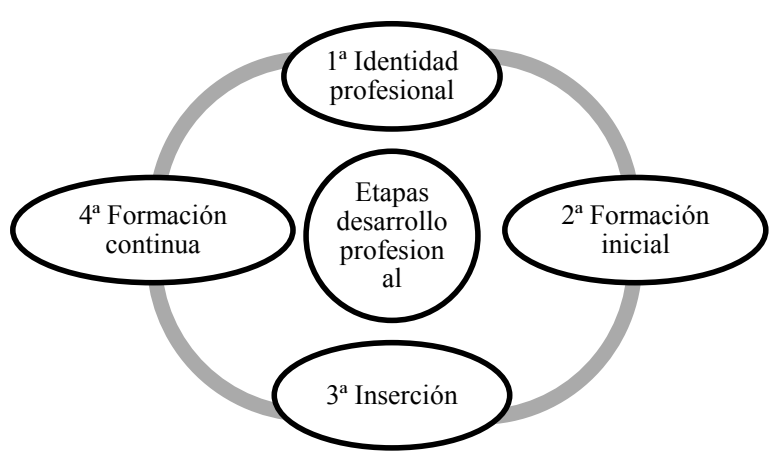

Fuente. Vaillant, 2016. 
La primera de las etapas está marcada por la búsqueda de la identidad profesional a través de las experiencias previas y teorías interiorizadas durante los estudios universitarios. De acuerdo con Rikard y Banville (2010) el primer año laboral “es un momento crítico para el crecimiento y desarrollo profesional que requiere de apoyo emocional y pedagógico de un mentor experto" (p. 245). Basándonos en las palabras de Marchesi (2007), señalamos que las continuas variaciones en la legislación educativa pueden llevar al profesor mentor principiante a etapas críticas en el desempeño de su profesión. El profesor mentor principiante no crea solo su propia identidad profesional, sino que es un proceso diario de convivencia con los iguales, docentes principiantes, alumnos e institución, lo que explica que debe ser un proceso activo y continuo de aprendizaje ante los nuevos acontecimientos educativos. A todo esto, se suma la capacidad de apertura al cambio incluyendo el manejo del rol como profesor mentor principiante y la adaptabilidad personal para responder de manera efectiva a las condiciones ambientales en constante cambio (Lindén, Ohlin \& Brodin, 2013). En los comienzos del desarrollo de la identidad profesional se encuentran intrínsecos múltiples obstáculos, desembocando en un "gran desequilibrio entre las exigencias de la labor propia y el conocimiento que se tiene sobre ella" (Herrera, Fernández, Caballero \& Trujillo, 2011, p. 219). Por lo que destacamos la aportación de Calderón (2020) quien defiende que existe diferentes fases en la trayectoria profesional, pero se detiene en la etapa de iniciación, como el momento en el cual se transita de la condición de estudiante a docente (p. 27). Como segunda etapa encontramos la formación inicial como primer escalón hacia el futuro laboral (Vaillant, 2016). La teoría, a veces, resulta inconexa en la práctica, ante esta situación, es significativo realizar procesos de asesoramiento en los primeros años de profesor mentor principiante de la mano del equipo de gestión de los centros educativos para orientar el futuro profesional.

Considerando nuestro estudio, establecemos que la primera y segunda fase (etapas de continuas inquietudes) necesitan de apoyo experto para poder hacer frente a las inseguridades o imprevistos. Del mismo modo, Herrera et al., (2011) defienden el apoyo institucional colectivo para "crear condiciones de desarrollo y de trabajo en torno a comunidades verdaderas de aprendizaje y que en definitiva se conformen como fuentes que emanan oportunidades y pretenden el logro transformador" (p. 218).

En la tercera etapa denominada Inserción mostramos la evolución de la formación inicial en mentoría a la entrada en el mundo laboral como un profesional íntegramente capacitado. Es por esto que el origen de la palabra "principiante" da comienzo a la andadura profesional. Esta etapa se puede prolongar en el tiempo, ya que es considerada compleja y significa el salto hacia la vida profesional, asumiendo una figura específica dentro de un entorno delimitado, en nuestro caso, las escuelas (Vaillant \& Marcelo, 2015).

Por último, cerramos las etapas con la formación continua, definida por Vaillant (2016) como el período de mejora en aspectos concretos del proceso de mentoría. Dicha formación permanente puede ser de tipo particular o grupal atendiendo a las demandas educativas. En el desarrollo profesional es vital la formación permanente ya que, en ocasiones, los profesores mentores principiantes comienzan a trabajar en centros educativos con "alta vulnerabilidad social, académica y económica, lo cual, aumenta la complejidad del puesto laboral" (Martínez, 2012, p. 122). Es por ello que se debe apoyar la formación y el aprendizaje permanente para dar respuesta al amplio abanico de contextos escolares. Ante ello, no podemos obviar que la formación continua es uno de los elementos principales que debe desarrollar el mentor principiante ya que "tanto la base pedagógica como la sabiduría 
de la práctica van construyendo su propio conocimiento unido a las prácticas profesionales" (Escudero, González \& Rodríguez, 2018, p. 157).

La mentoría unida al desarrollo profesional debe ir avanzando en las etapas descritas anteriormente por Vaillant (2016) teniendo en cuenta las características particulares. A través de la Figura 2 denotamos que se convierte en una evolución longitudinal (Crisp \& Cruz, 2009, p. 529).

Figura 2. Etapas en la mentoría

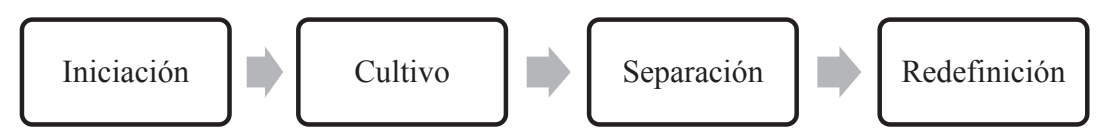

Fuente. Elaboración propia (Crisp y Cruz, 2009).

1. Etapa de iniciación: está comprendida entre los 6 primeros meses y el año de profesión laboral. Como bien indica el título de esta primera etapa es considerada como el inicio de la mentoría con los primeros contactos de la relación de mentor y docente principiantes.

2. Etapa de cultivo: cuenta con una duración de 2 a 5 años y va en la línea de la evolución en la mejora de las funciones del rol de mentor.

3. Etapa de separación: durante el desarrollo de esta fase cabe destacar que se consigue la autonomía laboral y pedagógica para desarrollar las funciones propias del rol de mentor y de esta forma evoluciona de mentor principiante a mentor experto. Las características más relevantes de esta fase de centran en las adaptaciones pedagógicas, curriculares o estructurales en el contexto organizacional educativo.

4. Etapa de redefinición: en el final de las fases, el mentor está suficientemente cualificado como experto para asesorar a nuevos mentores o continuar su función de forma crítica, autónoma y reflexiva.

El desarrollo profesional del profesor mentor principiante debe contar con una serie de competencias defendidas por Fernández-Salinero, Belando y González (2017, p. 70) mostradas en la Figura 3:

Figura 3. Características de la mentoría.

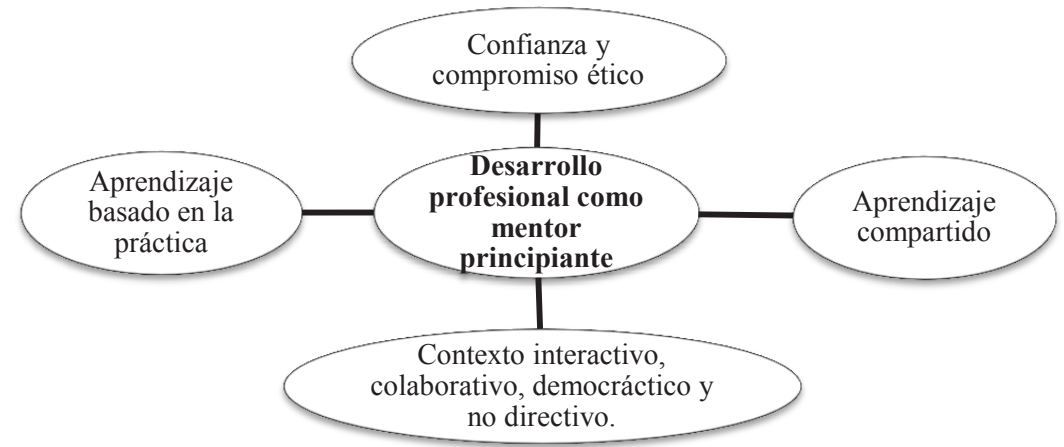

Fuente. Elaboración propia (Fernández-Salinero, Belando y González, 2017). 
Como podemos observar en la Figura 3, una de las competencias principales que sustenta la mentoría es el vínculo de confianza y el compromiso ético. A su vez, es todo un aprendizaje compartido tanto individual como grupal atendiendo al contexto en el que se desenvuelve y destacando el diálogo continuo como estrategia de mejora. Por lo que:

fomentar y acrecentar la autonomía del otro, a través de una actitud permanente de indagación que permita afrontar los problemas como retos profesionales que requieren buscar, pensar y construir -entre todos- nuevas alternativas, recursos y estrategias de intervención que mejoren el aprendizaje de los estudiantes (Vezub, 2011, pp. 111-112).

Es conveniente que el profesor mentor principiante cuente con retroalimentación formativa y trabajo en red con otros compañeros que comparten el rol. A través de este diálogo entre mentores principiantes se desenvuelven estrategias de mejora e innovación educativa. Decisivamente los profesores mentores principiantes, en su primer año de desarrollo profesional, pasan por una serie de obstáculos ligados al continuo aprendizaje basado en la práctica creándose un vínculo entre la formación inicial y la realidad laboral.

\section{METODOLOGÍA}

El propósito general planteado para esta investigación consiste en conocer y analizar el desarrollo profesional docente en el mentor principiante, teniendo en cuenta antecedentes formativos/profesionales y por consiguiente, posibles obstáculos y necesidades formativas/ profesionales surgidos durante el periodo de mentoría.

El enfoque metodológico es íntegramente cualitativo con la finalidad de estudiar vivencias, conocimientos, actitudes, etc., de los participantes en la investigación a partir de una serie de instrumentos concretos como son: guías de autopresentación, biogramas e incidentes críticos. Todos los instrumentos son de corte cualitativo ya que nos orientan a conocer y analizar "las experiencias de las personas en detalle" (Hennink, Hutter \& Bailey, 2011, pp. 8-9). Según Castro y Castro (2001) el método cualitativo se puede definir como un conjunto de acciones ordenadas estableciendo un proceso de investigación para lograr el objetivo principal, el conocimiento. En nuestro estudio, la metodología cualitativa es un proceso individualizado de profundización en los obstáculos y necesidades formativas y profesionales desde el rol del profesor mentor principiante respecto a las características personales descritas oralmente y posteriormente transcritas para su análisis cualitativo.

\subsection{POBLACIÓN Y MUESTRA}

En esta investigación han participado un total de 10 mentores seleccionados entre los participantes en el Programa INDUCTIO. Los criterios de selección para la participación han sido de tipo formativo (nivel académico de especialidad en alguna temática educativa, buena expresión oral y escrita, buena cultura general), laboral (antecedentes y tiempo de servicio, formación profesional, experiencia y competencia tecnológica) y personal (buenas relaciones interpersonales y actitud profesional positiva). En cuanto a los requisitos complementarios se encuentran: experiencia formativa (coordinación/ participación en: proyectos o planes de innovación docente, proyectos de mejora escolar, actividades 
de formación docente como formador, experiencia en acompañamiento de alumnos en prácticas de formación del profesorado y diseño materiales didácticos formativos) y competencia tecnológica (gestión documentos digitales, herramientas de comunicación digital y uso de plataformas tecnológicas). Esta última es imprescindible puesto que la formación recibida es tanto presencial como a distancia a través de la plataforma del programa, correo electrónico y aplicaciones móviles. Y otros imprescindibles como la disponibilidad y disposición para desplazarse a uno o varios centros escolares y dedicación a tiempo completo.

Tabla 1. Participantes y características

\begin{tabular}{|l|l|l|l|}
\hline $\begin{array}{l}\text { Número de } \\
\text { participantes }\end{array}$ & Intervalos de edad & Cualificación académica & Cargo laboral \\
\hline 3 & $35-40$ años & $\begin{array}{l}\text { Licenciatura en Educación } \\
\text { Básica e Inicial; especialidad en } \\
\text { Acompañamiento Pedagógico. }\end{array}$ & $\begin{array}{l}\text { Coordinador docente } \\
\text { pedagógico }\end{array}$ \\
\hline 3 & $41-45$ años & $\begin{array}{l}\text { Licenciatura en Educación Básica } \\
\text { e Inicial; maestría en Gestión de } \\
\text { Centros Educativos; licenciatura } \\
\text { en Biología y Química }\end{array}$ & $\begin{array}{l}\text { Coordinador docente } \\
\text { pedagógico }\end{array}$ \\
\hline 4 & $46-52$ años & $\begin{array}{l}\text { Licenciatura en Educación } \\
\text { Básica e Inicial; especialidad en } \\
\text { Educación Superior }\end{array}$ & $\begin{array}{l}\text { Coordinador docente } \\
\text { pedagógico y Profesor } \\
\text { de Universidad }\end{array}$ \\
\hline
\end{tabular}

El proceso de selección de los mentores ha sido aleatorio y basado en características comunes como son: antecedentes formativos y laborales (todos han sido anteriormente coordinadores pedagógicos) y el rango de edad (muestra significativa desde los 35 a los 52 años). Cabe destacar que el género mayoritario es el femenino.

En la Tabla 1 podemos observar el número de participantes por cada intervalo de edad junto a la cualificación académica y el cargo laboral. Las edades de los 10 sujetos seleccionados oscilan en los siguientes intervalos:

a) De 35 a 40 años: 3 mentores (30\%)

b) De 41 a 45 años: 3 mentores (30\%)

c) De 46 a 52 años: 4 mentores (40\%)

En cuanto a la cualificación académica, contamos con licenciaturas en educación básica e inicial (8), maestría en gestión de centros educativos (2), licenciatura en biología y química (1), especialidad en Educación Superior (1) y especialidad en acompañamiento pedagógico (1). La mayoría coinciden en experiencias formativas en educación básica e inicial. En lo que se refiere al cargo laboral anterior al desempeño del rol de mentor principiante, destaca el de coordinador docente pedagógico, figura enclavada en el sistema educativo dominicano como agente asesor-pedagógico de los docentes. 


\subsection{CONTEXTUALIZACIÓN}

A continuación, presentamos el mapa de República Dominicana dividido por regionales y distritos y a su vez iniciales desde la A a la J que pertenecen a los profesores mentores principiantes participantes en este estudio.

Es destacable conocer que cada mentor pertenece a una regional y distrito diferente, por lo que su labor profesional la realizan en la que pertenecen (algunas regionales con largas distancias en los centros educativos).

Gráfico 1. Mapa asignación mentores principiantes

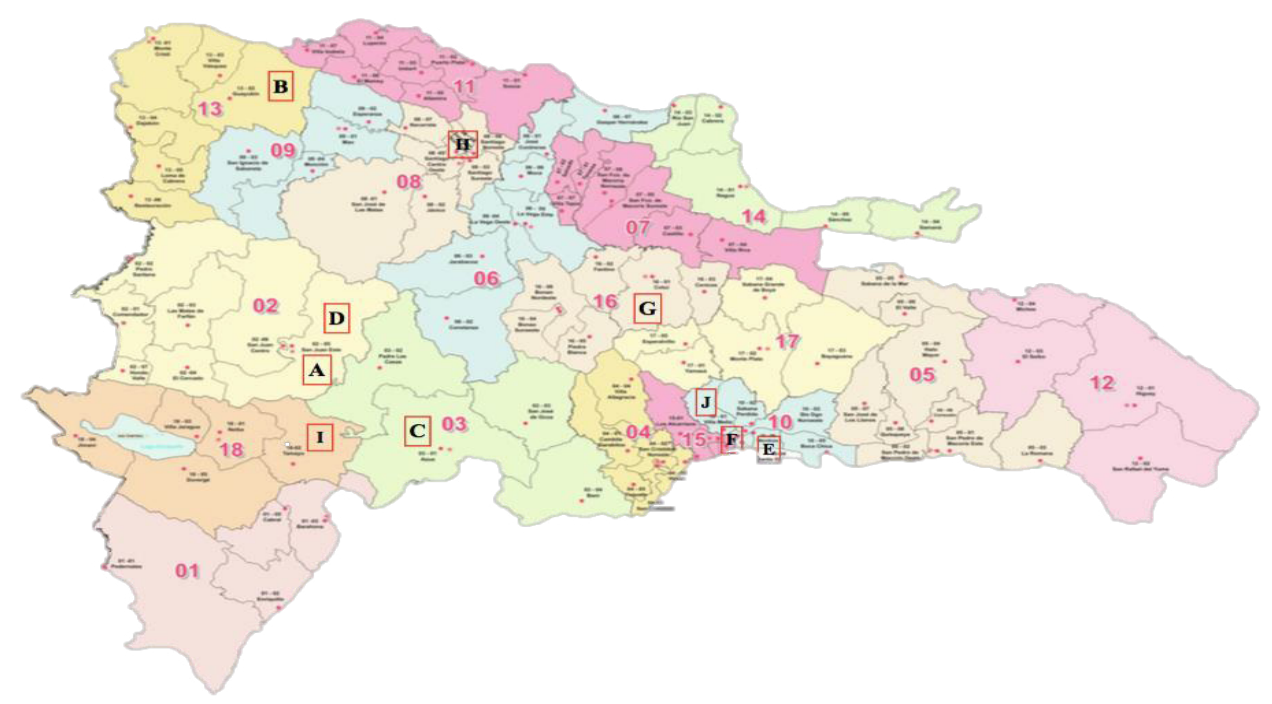

Como podemos observar en el mapa, los mentores A y D, coinciden en la misma regional y distrito debido al gran número de docentes principiantes que tienen que asesorar durante el primer año de iniciación a la práctica profesional en la zona. Los mentores principiantes restantes se ocupan de la regional y distrito donde tienen sus viviendas habituales. Es relevante destacar que las visitas a los centros escolares se realizan una vez por semana debido a que tan solo tienen un docente principiante asignado en cada centro educativo. En total cuentan con 10 docentes principiantes cada mentor por lo que tienen que visitar a la semana 10 centros educativos distribuidos en la regional y distrito asignado. Por lo general, los centros educativos están situados en zonas urbanas pero algunos distritos se encuentran en zonas rurales caracterizados por la marginalidad y dependencia, supeditados a las zonas urbanas que han concentrado los más altos niveles de crecimiento socioeconómico (Por \& Ramírez, 2004, p. 16). Esta circunstancia hace que existan desigualdades temporales cuando los mentores principiantes se trasladan a los centros. Las zonas rurales cuentan con bosques y caminos difíciles de transitar en coche, autobús o moto, por lo que en numerosas ocasiones han tenido que desplazarse a pie repercutiendo en el tiempo disponible para la labor de la mentoría. 


\subsection{INSTRUMENTOS}

Los instrumentos de investigación de corte cualitativo utilizados para la recogida de datos son las guías de autopresentación, los biogramas y los incidentes críticos, los cuales presentamos a continuación.

\subsubsection{Guías de autopresentación}

Estas guías nos permiten conocer los datos biográficos principales a través de 5 cuestiones realizadas en una entrevista personal. Es una mera descripción biográfica sobre datos personales, formativos, antecedentes laborales, etc., que define cómo es la persona en el ámbito profesional y personal (Domingo y Fernández, 1999).

Para la validación del instrumento es a través del juicio de expertos (concretamente 3) con modificaciones en el ámbito semántico y ortográfico de escasa relevancia. Este instrumento de carácter descriptivo ha sido respondido por los mentores durante los meses de Enero-Febrero del año 2016. La forma principal de contacto ha sido en persona durante la estancia en República Dominicana a finales del mes de enero del año 2016 y también por llamadas telefónicas a través de la aplicación Whatsapp y grabadas en audio.

\subsubsection{Biogramas}

Este instrumento es definido como una representación gráfica de tipo biográfico y cronológico en el que se destacan tiempos y lugares determinantes en la trayectoria profesional y personal del participante. López (2015) lo define como "recurso de análisis gráfico que expresa los acontecimientos y situaciones formativas coincidentes en nuestros participantes" (p. 82). Según los autores Domingo y Fernández (1999) es "necesario realizar una reflexión previa para organizar los elementos fundamentales de forma clara y concisa" (p. 46). López (2015) nos detalla el propósito principal de la realización de los biogramas:

(...) permiten conocer las trayectorias individuales, para posteriormente construir un mapa global de todos los mentores, con el fin de observar los puntos coincidentes a través del biograma global. En este proceso de reconstruir las vivencias compartidas por los mentores participantes por medio del biograma global se inicia la contextualización de las experiencias educativas en la infancia, lo cual es el primer paso para categorizar posteriormente dichas experiencias y establecer las relaciones entre ellas (p. 84).

La aplicación de este instrumento tiene el propósito de analizar los antecedentes formativos y profesionales de los mentores, delimitar y definir las necesidades formativas del mentor e identificar los obstáculos/barreras en el desempeño del rol de mentor.

Los biogramas versan sobre la trayectoria formativa y profesional. La modalidad ha sido por escrito durante la visita de los participantes a Sevilla en el mes de septiembre de 2016.

Este instrumento ha sido recogido de una propuesta de Domingo y Fernández (1999) detectando los acontecimientos o hechos significativos en la trayectoria formativa y profesional del profesor mentor principiante, fecha y valoración de cada hecho. Para ello 
hemos seguido la plantilla que proponen los autores citados anteriormente en el libro Técnicas para el desarrollo personal y formación del profesorado (1999).

La validación ha sido similar a la del instrumento guías de autopresentación eligiendo el juicio de expertos (concretamente 3), los cuales, están inmersos en esta investigación.

\section{c) Incidentes críticos}

Este instrumento se considera una herramienta ligada a la reflexión, bajo la experiencia y análisis de la propia práctica. A través de él se pretende identificar los puntos clave tratados como obstáculos o dificultades en el aprendizaje significativo y el conocimiento pedagógico durante la trayectoria formativa y profesional del profesor mentor principiante. Los tópicos a indagar en este instrumento son: el contexto, la descripción de la problemática, las posibles causas y las posibles soluciones que propone el sujeto (González, Pérez \& Escartín, 2003).

La subjetividad implícita en los incidentes críticos debe ser tratada desde la interacción de mentores e investigador. Dicho instrumento se puede analizar por diferentes vías:

- Incidente tratado como un problema junto a la posible solución de estos.

- Apoyo pedagógico y didáctico respecto al análisis de las posibles soluciones de tipo profesional.

Siguiendo a Hernández (2013) detallamos que "la eficacia de la técnica, al centrarse en el análisis holístico, identifica los principales hitos significativos de los informantes" (p. 92). Con este instrumento se busca el "rechazo a la situación vivenciada u observada con una muestra de las secuelas negativas resultantes y a su vez, la indagación de soluciones a dicho incidente" (González et al., 2003, p. 43).

La validación del diseño del instrumento es mediante el juicio de expertos realizando modificaciones en algunas cuestiones a investigar y centrándolas en aspectos formativos y laborales y no tanto personales.

\subsection{PROCEDIMIENTO DE RECOLECCIÓN Y ANÁLISIS DE DATOS}

En este epígrafe presentamos los diferentes instrumentos utilizados para la recogida de datos investigativos y su posterior análisis. En la Tabla 2 que mostramos a continuación observamos los diferentes instrumentos y categorías diseñados para esta investigación.

Tabla 2. Categorías principales de los instrumentos

\begin{tabular}{|l|l|}
\hline Instrumentos & Categorías \\
\hline Guías de autopresentación & $\begin{array}{l}\text { Intervalos de edad; formación académica; regional y distrito; } \\
\text { antecedentes laborales }\end{array}$ \\
\hline Biogramas & Cronología; acontecimientos; valoración \\
\hline Incidentes críticos & $\begin{array}{l}\text { Relación mentor-docente principiante; relación mentor-mentor; } \\
\text { relación mentor-equipo directivo de escuelas; superación de } \\
\text { obstáculos; mediación entre roles; uso de las TICs }\end{array}$ \\
\hline
\end{tabular}




\subsubsection{Instrumento guías de autopresentación}

La guía para la autopresentación es analizada mediante un sistema de categorías fundamentado en la propuesta de Miles y Huberman (1994) siguiendo un doble proceso: emergente y fundamentado en los esquemas teóricos de partida y usando un sistema de codificación descriptivo. Las categorías señaladas para este instrumento son: intervalos de edad, formación académica, regional y distrito y antecedentes laborales. Cabe destacar que para la validación del sistema de categorías diseñado hemos recurrido a tres codificadores con identidades profesionales similares (docentes universitarios) y expertos en el desarrollo profesional, cuyo proceso ha sido riguroso y minucioso en el diseño de las cuestiones a indagar con dicho instrumento. Este proceso se ha visto necesario por estar inmersos en un análisis cualitativo emergente siguiendo las siguientes fases: codificación individual, puesta en común de los códigos, colocación individual de códigos en el instrumento y puesta en común de la colocación de estos.

\subsubsection{Instrumento biogramas}

En cuanto a los biogramas, el análisis también ha sido fundamentado en la propuesta de Miles y Huberman (1994) a través de las principales categorías de cronología de los hechos, acontecimiento y valoración; las cuales han sido validadas por expertos.

\subsubsection{Instrumento incidentes críticos}

El análisis de los datos de los incidentes críticos está basado en categorías concernientes a la tipología de incidentes críticos señalados por los profesores mentores principiantes en este estudio. Adelantamos que la tipología versa sobre las relaciones de los profesores mentores principiantes y la detección y superación de obstáculos y necesidades en la trayectoria formativa y profesional.

El análisis de los datos para cada instrumento específico ha sido procesado y analizado mediante el uso del programa de análisis de datos cualitativos MAXQDA 2020 permitiéndonos estructurar los datos con diferentes niveles de análisis y establecer conexiones mediante criterios. A su vez, el programa informático nos aporta facilidades para el análisis individualizado de las categorías y sus correspondientes códigos, comprobando en cada instrumento donde se sitúan los mismos.

\section{RESULTADOS Y DISCUSIÓN}

En este apartado damos respuesta a las cuestiones de investigación planteadas al principio del artículo respecto a los resultados obtenidos en cada uno de los instrumentos de forma individualizada (profesores mentores principiantes nombrados desde la letra A a la J, según orden alfabético y de manera confidencial) y posteriormente presentamos los resultados generales bajo tres líneas básicas (1, 2 y 3 ).

\subsection{GUÍAS DE AUTOPRESENTACIÓN}

Inicialmente presentamos la Figura 4 haciendo alusión a los datos recogidos en las Guías de Autopresentación a través de los cuales detallamos que existen 3 intervalos de edad que van desde los 35 hasta los 52 años. 
En cuanto a la formación académica, podemos observar que existe una diversidad en las tipologías de carreras y especialidades, pero siempre en el ámbito educativo. Destacamos que los mentores principiantes siguen formándose y asistiendo a numerosas jornadas y congresos para mejorar su propia práctica, tanto en República Dominicana como ocurre también en otros países como Chile o España.

Figura 4. Resultados del instrumento guías de autopresentación

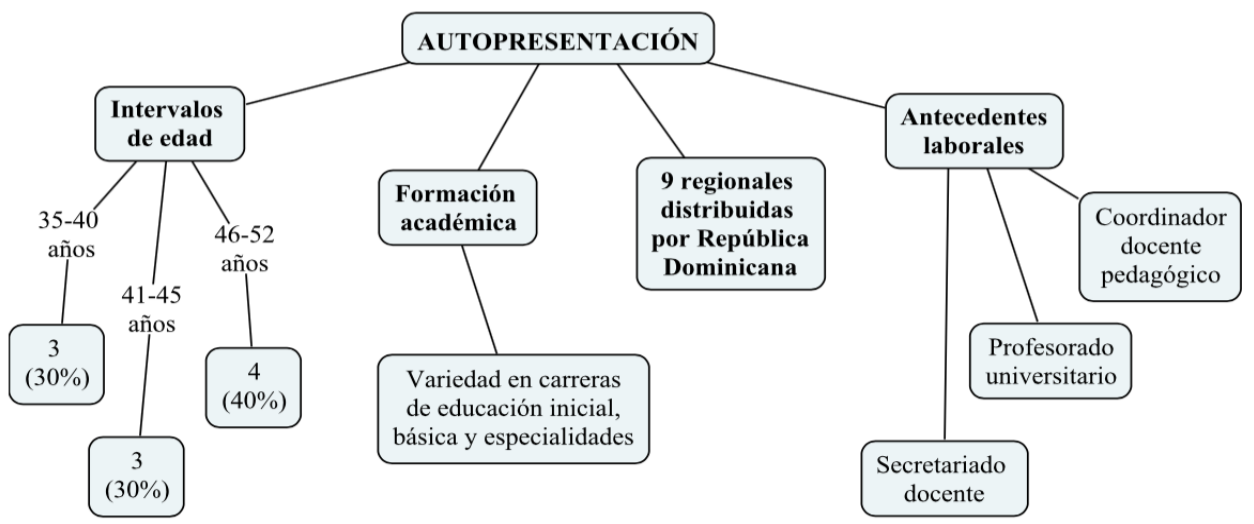

Respecto a los antecedentes laborales señalamos que todos los mentores principiantes han sido anteriormente profesores de educación inicial, básica, media o multigrado, por lo que cuentan con más de cinco años de experiencia como docentes. La mayoría de ellos, concretamente 8, han compartido el cargo de coordinador docente pedagógico en diferentes niveles educativos. Los resultados están enclavados en los centros educativos de República Dominicana con funciones generales como son el asesoramiento, planificación, diálogo, orientación, etc. a todos los docentes de una escuela. Destacamos los antecedentes laborales como diferencia a las ocupaciones anteriores del resto de participantes debido a que también son profesores de Enseñanza Superior en Instituto Superior de Formación Docente Salomé Ureña (ISFODOSU), institución pública y con carácter estatal. Debido a la simultaneidad de cargos laborales han tenido que dedicar menos tiempo a la mentoría que los demás compañeros mentores y asesorar a menos docentes principiantes. Por otro lado, en el caso de otros mentores principiantes, cuentan con más de 20 años de experiencia en las escuelas con cargos como el de Secretariado docente en liceos.

\subsection{BIOGRAMAS}

Atendiendo al segundo de los instrumentos, biogramas, presentamos el mapa conceptual con los resultados obtenidos para cada categoría.

Los biogramas analizados tratan sobre el conocimiento acerca de la trayectoria formativa y profesional de los mentores principiantes participantes en nuestro estudio. Cada una de las categorías presentadas cuenta con un código determinado por las primeras cuatro letras de las mismas. De este modo, son los siguientes: cronología (CRON), acontecimientos o lugares (ACON) y valoración (VALO). 


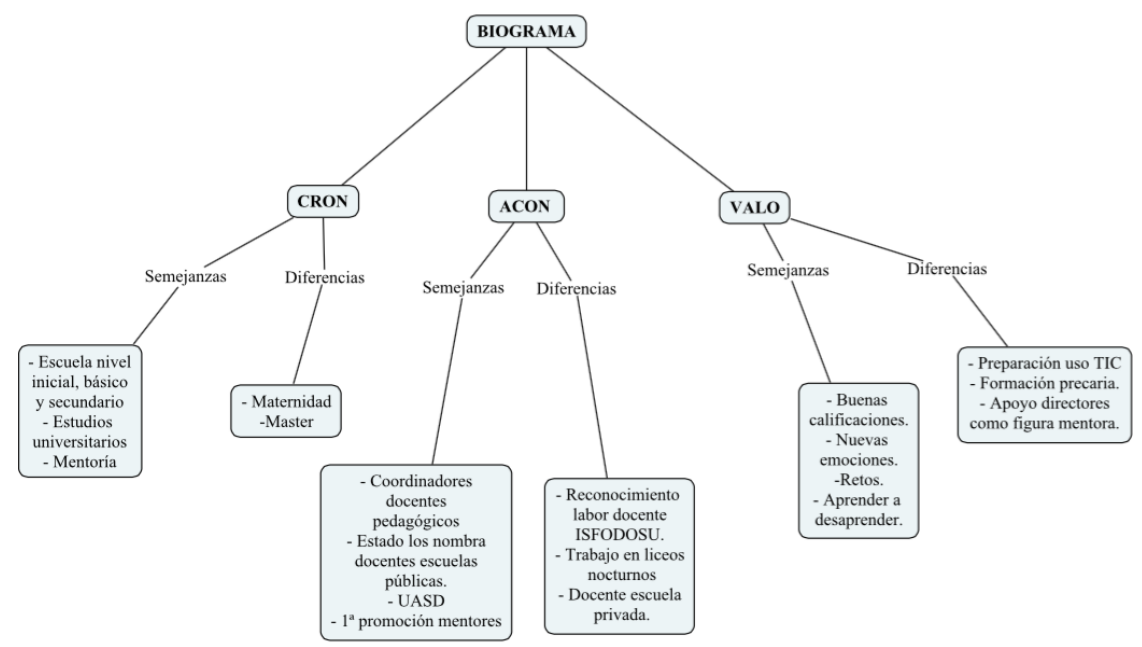

Como podemos observar en la Figura 5 las semejanzas formativas siguen la línea anteriormente descrita, con la diferencia que en dos casos aislados, los estudios fueron prolongados en el tiempo debido a la maternidad de una mentora y a estudios de Máster. Los acontecimientos más destacados en los biogramas se refieren a la ocupación compartida del cargo de coordinador docente pedagógico; y posterior nombramiento (por el Estado de República Dominicana) como mentores perteneciendo a la primera promoción en el país. En cuanto a las diferencias significativas en esta categoría detectamos trabajos nocturnos en liceos, reconocimiento docente universitario por parte del Instituto Superior de Formación Docente Salomé Ureña (ISFODOSU) y docencia en escuela privada. Las valoraciones positivas de los mentores son las buenas calificaciones obtenidas en las trayectorias profesionales junto a las nuevas emociones y retos en el avance de la formación. Por otro lado, también existen valoraciones negativas como es la formación precaria recibida en los primeros niveles educativos y escasa formación en el uso de las TICs. Señalamos una de las diferencias en las valoraciones puesto que solo un participante ha subrayado la importancia de la labor de los directores como mentores de los mentores principiantes.

A continuación, presentamos el biograma general y común de los participantes por fechas y acontecimientos relevantes:

Gráfico 2. Biograma general de los participantes

\section{Biograma común sobre las trayectorias profesionales y formativas}

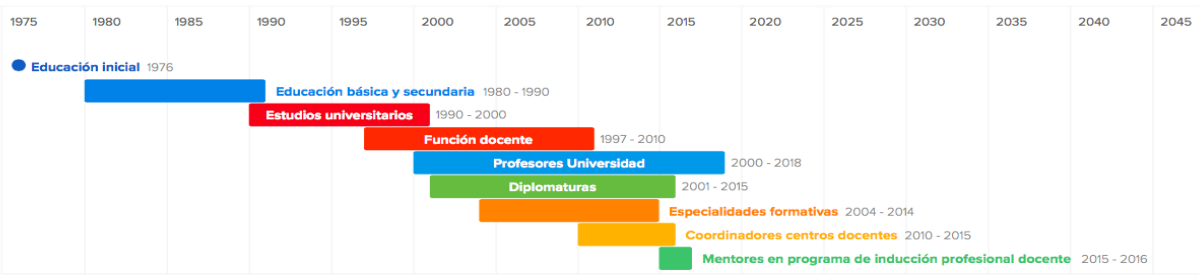


Por lo general todos los mentores principiantes tienen una amplia formación académica y profesional. Por el contrario, algunos de ellos, comenzaron su trayectoria formativa en ciencias naturales o química, destacando que durante esta evolución formativa reflexionaron acerca de su futuro laboral. En cuanto a los cargos laborales actuales, cuatro de los participantes continúan como mentores de docentes principiantes. Este dato es relevante debido a que los demás (6 restantes) no cuentan con el apoyo institucional para continuar y afianzar la figura del mentor en el sistema educativo dominicano y han vuelto a ocupar los cargos anteriores al de mentor (coordinador docente pedagógico, profesor universitario y técnico distrital). En el biograma común a todos los mentores también observamos que el cargo de coordinador docente oscila entre 2010 y 2015 debido a que se deben cumplir una serie de requisitos previos para acceder a este puesto laboral. Según el Instituto Dominicano de Evaluación e Investigación de la Calidad Educativa (IDEICE, 2014, p. 15) describe detalladamente las condiciones de acceso a mentor, las cuales, presentamos seguidamente:

Figura 6. Requisitos para ser profesor mentor principiante

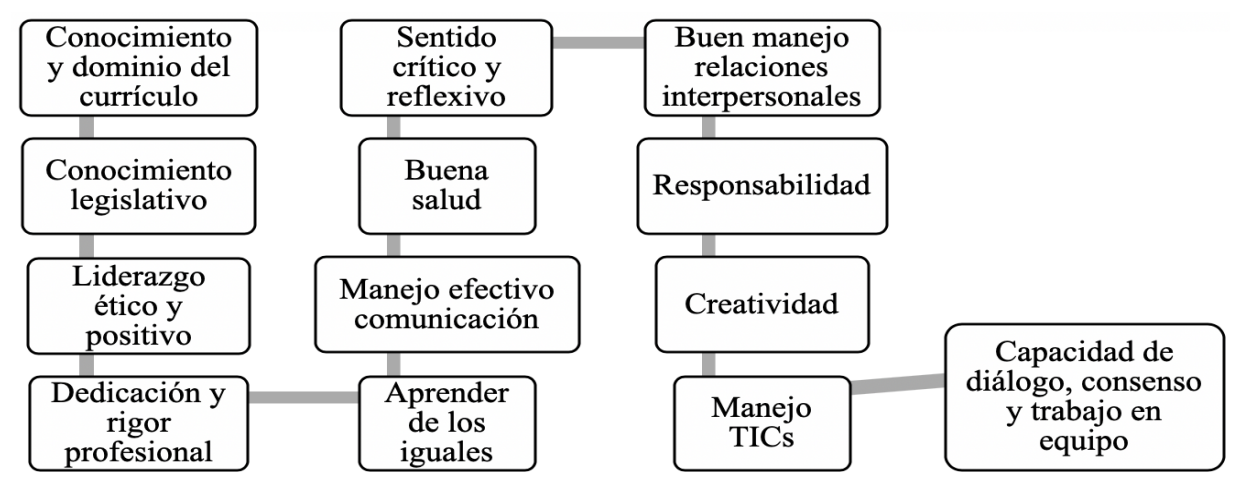

Todos los requisitos presentados requieren un tiempo de servicio en el sistema educativo dominicano y nuestros participantes cuentan con más de 10 años de experiencia laboral en educación. La razón de no continuar desarrollándose profesionalmente como mentores (6 de ellos) se justifica con la falta de consolidación y apoyo institucional a esta nueva figura laboral, es por esto que, al no permanecer dicho rol de forma oficial, los mentores vuelven a ocupar el puesto de coordinador. En el caso de los 4 participantes que siguen siendo mentores actualmente (ya son mentores expertos) es gracias al apoyo regional-distrital que apuestan por la mentoría, pero no a nivel gubernamental-institucional.

\subsection{INCIDENTES CRÍTICOS}

Atendiendo a la tipología de incidentes críticos (25 en total) analizamos los datos dividiendo los resultados en 2 mapas conceptuales específicos de tres categorías cada uno para su mayor profundización. Primero, analizamos las categorías afines con las relaciones del mentor y en un segundo momento las categorías de superación de obstáculos, mediación y uso de las TICs. 
En esta figura analizamos la categoría denominada "relaciones del mentor".

Figura 7. Resultados categoría "relaciones del mentor"

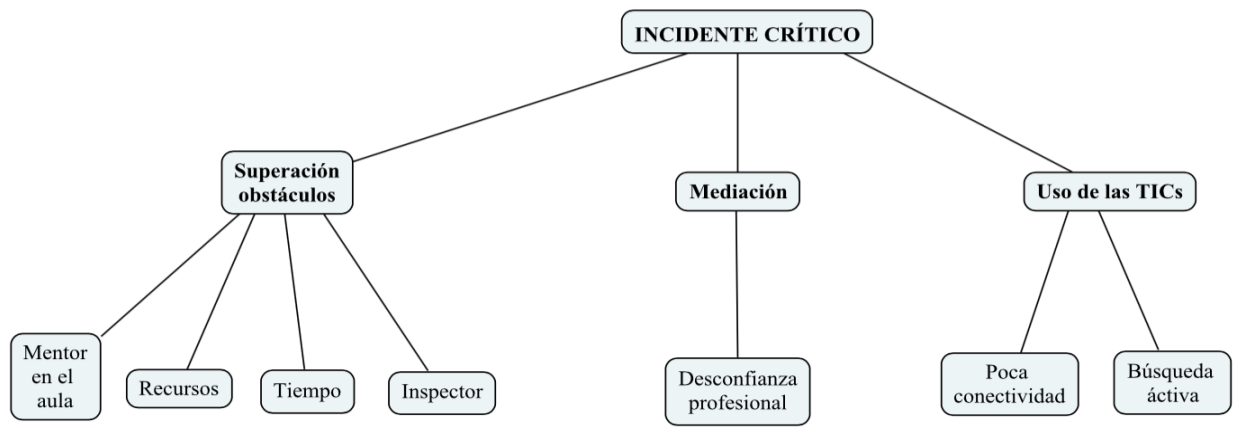

Como podemos observar a la izquierda de la Figura 7, la relación entre mentor y docente principiante, es continua y los incidentes críticos surgen a partir de los conflictos en el aula, debido en estos casos, a la falta de motivación del alumnado en el proceso de aprendizaje. A su vez, la pobreza en el contexto inmediato de las escuelas del país repercute en la obtención de recursos didácticos, pedagógicos y tecnológicos en la enseñanza. Esto supone que el profesor mentor principiante indague en nuevos recursos y herramientas gratuitas para mejorar las situaciones de clase. Por otro lado, todos los docentes principiantes se reúnen en círculos de aprendizaje con el profesor mentor principiante asignado para resolver dudas, compartir experiencias, sentimientos, etc.

En el centro de la Figura 7 tenemos las relaciones entre iguales (mentores) subrayando que entre ellos mismos resuelven sus dudas, inquietudes, comparten éxitos, etc. En la mayoría de las ocasiones este registro es mediante la aplicación Whatsapp debido a la lejanía entre regionales y distritos donde residen. Los temas tratados a través de este medio son por lo general de necesidades formativas (obtención de recursos digitales y educativos, realización de seminarios tecno-pedagógicos, etc.) y profesionales (dudas en el asesoramiento individual y grupal, mejora de la capacidad de diálogo con los equipos directivos de las escuelas y buenas prácticas).

Las relaciones entre mentor y equipo directivo de las escuelas van en la línea de una falta de empatía latente que conlleva a una falta de diálogo para comprender las funciones de la mentoría. Es relevante atender a la necesidad de confianza de los mentores principiantes por parte de los directores de los centros educativos, máxima figura representativa de cada institución educativa.

Seguidamente presentamos la Figura 8 que nos muestra las 3 últimas categorías del instrumento Incidente Crítico. 
Figura 8. Resultados categoría "superación de obstáculos, mediación y uso TICs"

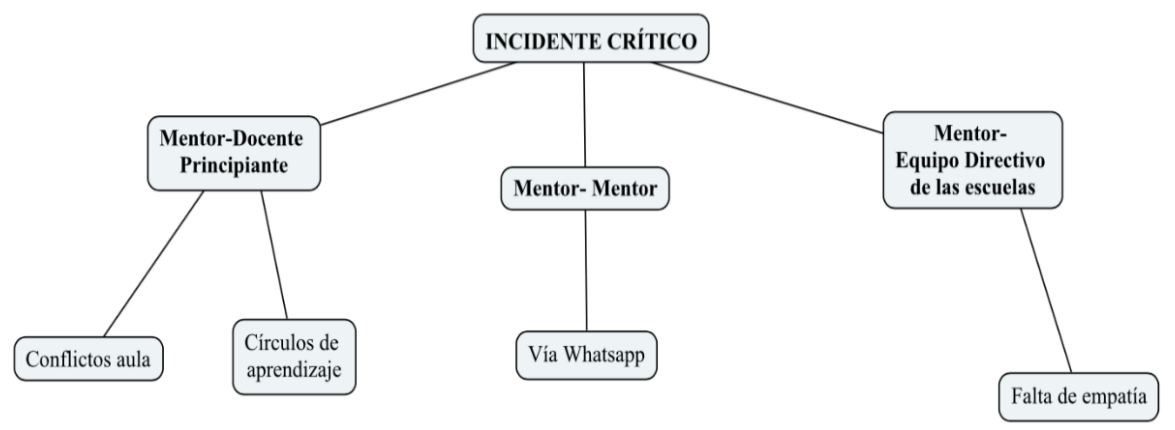

En la superación de obstáculos nos encontramos principalmente:

- Mentor en el aula: observación participante desempeñando el rol de docente.

- Tiempo de dedicación completo a la mentoría.

- Recursos: deben contar con una base de tipo pedagógico y lúdico.

- Inspector: en ocasiones, el mentor es visionado por el docente principiante como un sujeto que evalúa todos sus movimientos y el mentor debe hacerle entender que no son sus funciones.

La mediación es un aspecto clave para el buen desarrollo de los roles individuales ya que señalan incidentes críticos en la línea de la desconfianza profesional de directores en docentes principiantes. El mentor resuelve mediando entre ambas figuras a través del diálogo permanente.

Se dan muchos incidentes críticos relacionados con el uso de las TICs debido a que la realidad latente es que los mentores cuentan con poca conectividad en algunas zonas de República Dominicana y deben superar habilidades tecnológicas como es la búsqueda activa de artículos, recursos, uso de redes sociales, etc.

A continuación, presentamos una tabla resumen y general donde destacamos las categorías, los participantes de este estudio, los tipos de incidentes críticos narrados y observaciones para cada una de las categorías. 
Tabla 3. Resultados generales Incidentes Críticos

\begin{tabular}{|c|c|c|c|}
\hline Categorías & Participantes & $\begin{array}{l}\text { Tipos de Incidentes } \\
\text { Críticos }\end{array}$ & Observaciones \\
\hline $\begin{array}{l}\text { Relación mentor- } \\
\text { docente principiante }\end{array}$ & $\begin{array}{l}\text { A, B, C, D, E, } \\
\text { F, H. }\end{array}$ & $\begin{array}{l}\text { Conflictos en el aula y } \\
\text { Mejoras educativas }\end{array}$ & $\begin{array}{l}\text { "Ayudó a mejorar las prácticas } \\
\text { dentro de las aulas de los } \\
\text { participantes y me sirvió como } \\
\text { motivación para continuar mi } \\
\text { desarrollo personal y } \\
\text { profesional" (mentor B). }\end{array}$ \\
\hline $\begin{array}{l}\text { Relación mentor- } \\
\text { mentor }\end{array}$ & H. & $\begin{array}{l}\text { Necesidad de compartir } \\
\text { experiencias, inquietudes, } \\
\text { dudas, recursos, etc. }\end{array}$ & $\begin{array}{l}\text { "Tenía a mis compañeros } \\
\text { cerca, en la distancia, a } \\
\text { través del móvil" (mentor D). }\end{array}$ \\
\hline $\begin{array}{l}\text { Relación mentor- } \\
\text { equipo directivo de } \\
\text { escuelas }\end{array}$ & I, J. & $\begin{array}{l}\text { Apoyo institucional por } \\
\text { parte de los directivos de } \\
\text { los centros }\end{array}$ & $\begin{array}{l}\text { "Falta de empatía del } \\
\text { director como apoyo a mi rol } \\
\text { como mentora" (mentor J). }\end{array}$ \\
\hline $\begin{array}{l}\text { Superación de } \\
\text { obstáculos }\end{array}$ & A, C, D, G, J. & $\begin{array}{l}\text { Conocimiento de la } \\
\text { realidad educativa de } \\
\text { las escuelas; formación } \\
\text { permanente; tiempo; } \\
\text { recursos. }\end{array}$ & $\begin{array}{l}\text { "Le expliqué a la docente } \\
\text { que yo no iba a evaluarla } \\
\text { y con aquello se marcó el } \\
\text { inicio de un nuevo concepto } \\
\text { de acompañamiento con una } \\
\text { función asesora hacia la } \\
\text { mejora" (mentor } \mathrm{H}) \text {. }\end{array}$ \\
\hline $\begin{array}{l}\text { Mediación entre } \\
\text { roles }\end{array}$ & $\mathrm{E}, \mathrm{F}, \mathrm{I}$. & $\begin{array}{l}\text { Confianza por parte de } \\
\text { los directores en los } \\
\text { nuevos roles como son } \\
\text { el de profesor mentor } \\
\text { principiante y los } \\
\text { docentes principiantes. }\end{array}$ & $\begin{array}{l}\text { "maestra un poco } \\
\text { desesperada, equipo de } \\
\text { gestión preocupado por la } \\
\text { situación. Sentimientos de } \\
\text { inseguridad, desmotivación, } \\
\text { desesperanza, etc. Ser } \\
\text { mediadora entre maestra } \\
\text { principiante y directora del } \\
\text { centro educativo, llevar a la } \\
\text { reflexión desde el rol que le } \\
\text { toca a cada uno en la escuela } \\
\text { en marco de respeto y con un } \\
\text { único propósito" (mentor D). }\end{array}$ \\
\hline Uso de las TICs & G, J. & $\begin{array}{l}\text { Mala conectividad a } \\
\text { Internet y formación } \\
\text { tecnológica. }\end{array}$ & $\begin{array}{l}\text { "Mejor dominio de recursos } \\
\text { tecnológicos" (mentor G). }\end{array}$ \\
\hline
\end{tabular}

\subsection{TRIANGULACIÓN DE INSTRUMENTOS}

En lo que se refiere a los resultados individuales de cada uno de los tres instrumentos presentados anteriormente, mostramos los resultados generales basados en las semejanzas y diferencias entre todos los instrumentos. Para su mejor visualización hemos creado tres líneas (1, 2 y 3) con características comunes de los profesores mentores principiantes. 
Gráfico 3. Obstáculos y necesidades en la trayectoria formativa/profesional de los profesores mentores principiantes

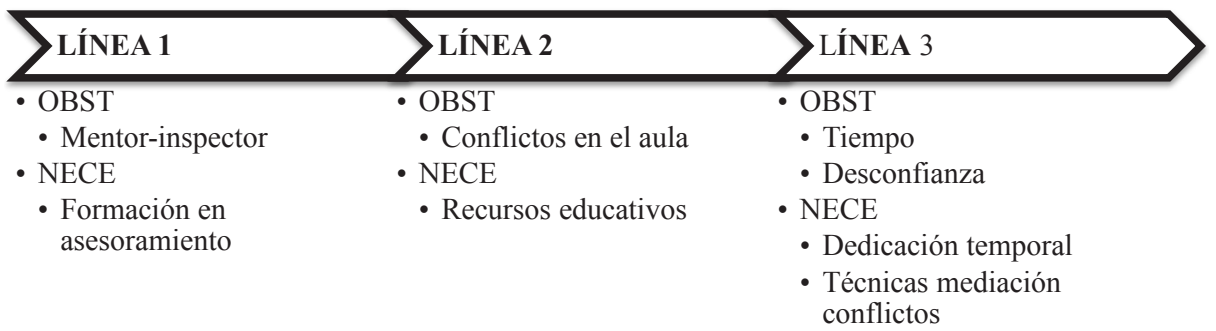

LÍNEA 1: los participantes pertenecientes a esta línea se encuentran en el rango de edad de 35-40 años de edad siendo anteriormente secretarios docentes en escuela pública. Los antecedentes formativos consisten en diplomatura y especialidad en secretariado docente. En los biogramas de esta línea detallamos que las nuevas emociones están muy marcadas debido a la falta de condiciones positivas en el puesto laboral anterior junto a la necesidad de seguir avanzando profesionalmente. Los nuevos retos se marcan cuando los mentores estudian y trabajan a la vez para poder pagarse sus estudios debido a que les rodeaban un contexto empobrecido, de ahí, la formación precaria. En esta línea, los incidentes críticos están relacionados con la visión de los mentores como inspectores que evalúan el día a día de los docentes principiantes en las aulas. Es por ello la necesidad de resolver este obstáculo para comenzar a mentorizar a los docentes, pasar de la figura de evaluador a la de mentor basado en las buenas prácticas.

LÍNEA 2: Intervalo de edad entre 41-45 años son los que se corresponden con los que coinciden en los antecedentes laborales bajo el rol de coordinador docente pedagógico. Están distribuidos por 9 regionales de República Dominicana. Al relacionar los resultados de la autopresentación con los biogramas detectamos que la formación inicial, básica y secundaria fue precaria. El cargo anterior a la mentoría, coordinador docente pedagógico, fue nombrado por el Estado y la formación académica fue en escuelas públicas y posteriormente en la Universidad Autónoma de Santo Domingo también de carácter público. A su vez señalan en su trayectoria formativa el comienzo preparatorio en el uso de las TICs. En uno de los casos, debido a la maternidad, la formación fue más lenta en los estudios secundarios. Todos comparten la idea del aprender a desaprender al iniciar la labor de mentoría. Aun así, ya ejerciendo el rol de mentor principiante, detallan algunos incidentes críticos durante su labor profesional conectando con asesoramiento a los docentes principiantes en temas como los conflictos en el aula. En cuanto a la relación con los iguales (mentores principiantes) destacamos que el intercambio de dudas, inquietudes, satisfacciones, etc. ha sido mediante la aplicación móvil Whatsapp sin tener apenas contacto presencial. La mayoría superan los obstáculos presentados como son la observación directa en el aula y los recursos disponibles de tipo educativo, pedagógico o tecnológico debido a la falta de conectividad en algunas regionales del país.

LÍNEA 3: el intervalo de edad se basa en los 46-52 años de edad correspondiente con los antecedentes laborales de docentes universitarios. Se ubican en una regional de República 
Dominicana y la formación académica es desde la escuela inicial hasta estudios universitarios. En los biogramas vinculamos la trayectoria formativa con el reconocimiento a la labor docente por parte de Instituto Superior de Formación Docente Salomé Ureña (ISFODO$\mathrm{SU})$. Cuentan con semejanzas con sus compañeros mentores en la preparación para el uso de las TICs y una formación inicial precaria. En el instrumento de los incidentes críticos señalan la falta de empatía del equipo de gestión en cuanto a la desconfianza profesional de la labor de los docentes principiantes y la propia de la mentoría. En estos casos, los mentores han tenido que mediar entre directores y docentes principiantes. En esta línea, el tiempo es el principal obstáculo para superar debido a la simultaneidad de puestos laborales.

Tabla 4. Resultados triangulación instrumentos por líneas

\begin{tabular}{|c|c|c|c|c|c|c|c|}
\hline 恚 & 疍 & 总 & 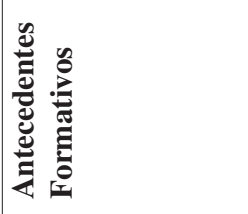 & 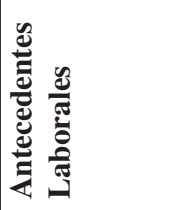 & 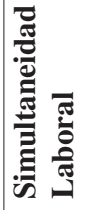 & 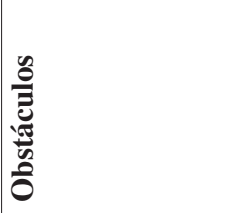 & 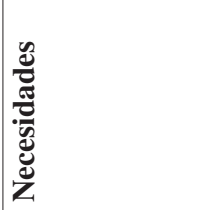 \\
\hline 1 & $41-45$ & 3 & $\begin{array}{l}\text { Educación } \\
\text { inicial, básica } \\
\text { y secundaria. } \\
\text { Licenciado } \\
\text { en Biología y } \\
\text { Química }\end{array}$ & $\begin{array}{l}\text { Secretario } \\
\text { Docente en } \\
\text { Liceo. }\end{array}$ & $\mathrm{NO}$ & $\begin{array}{l}\text { Docentes } \\
\text { principiantes } \\
\text { ven la figura de } \\
\text { mentor como } \\
\text { inspectores } \\
\text { que evalúan su } \\
\text { práctica laboral. }\end{array}$ & $\begin{array}{l}\text { Formación } \\
\text { específica en } \\
\text { asesoramiento } \\
\text { al docente } \\
\text { principiante. }\end{array}$ \\
\hline 2 & $46-52$ & 4 & $\begin{array}{l}\text { Educación } \\
\text { inicial, básica } \\
\text { y secundaria. } \\
\text { Licenciado en } \\
\text { Educación Básica. } \\
\text { Maestría en } \\
\text { gestión de centros } \\
\text { educativos. } \\
\text { Especialidad en } \\
\text { acompañamiento } \\
\text { pedagógico. } \\
\text { Máster. }\end{array}$ & $\begin{array}{l}\text { Docente } \\
\text { nivel básico y } \\
\text { Coordinador } \\
\text { pedagógico } \\
\text { docente }\end{array}$ & NO & $\begin{array}{l}\text { Asesoramiento } \\
\text { específico } \\
\text { sobre conflictos } \\
\text { en el aula; } \\
\text { escasos recursos } \\
\text { educativos en } \\
\text { los centros } \\
\text { escolares. }\end{array}$ & $\begin{array}{l}\text { Mayor contacto } \\
\text { entre mentores } \\
\text { para resolver } \\
\text { dudas, compartir } \\
\text { experiencias, } \\
\text { etc.; uso de } \\
\text { las TICs } \\
\text { para indagar } \\
\text { en recursos, } \\
\text { artículos, blogs, } \\
\text { etc. }\end{array}$ \\
\hline 3 & $35-40$ & 3 & $\begin{array}{l}\text { Educación } \\
\text { inicial, básica } \\
\text { y secundaria. } \\
\text { Licenciado } \\
\text { en educación } \\
\text { básica. Maestría } \\
\text { en Enseñanza } \\
\text { Superior y } \\
\text { formador de } \\
\text { formadores. }\end{array}$ & $\begin{array}{l}\text { Director y } \\
\text { profesor } \\
\text { de escuela } \\
\text { multigrado. } \\
\text { Docente } \\
\text { enseñanza } \\
\text { superior. }\end{array}$ & SI & $\begin{array}{l}\text { Desconfianza } \\
\text { laboral en el } \\
\text { mentor por } \\
\text { parte del equipo } \\
\text { directivo de } \\
\text { las escuelas } \\
\text { asignadas; } \\
\text { tiempo asignado } \\
\text { para la mentoría. }\end{array}$ & $\begin{array}{l}\text { Formación } \\
\text { en técnicas } \\
\text { de mediación } \\
\text { de conflictos; } \\
\text { mayor espacio } \\
\text { temporal para } \\
\text { desarrollar el } \\
\text { puesto laboral de } \\
\text { mentor. Alivio } \\
\text { de otras cargas } \\
\text { laborales. }\end{array}$ \\
\hline
\end{tabular}


A través de los datos recogidos descubrimos que comparten el rol de profesor mentor principiante con otros cargos laborales del sistema educativo dominicano de forma simultánea, entre los que se encuentran: coordinadores docentes pedagógicos, docentes universitarios, técnicos distritales, etc., por lo que esta desventaja temporal en cuanto a la dedicación para el desempeño del rol de mentor se convierte en un obstáculo para el propio desarrollo profesional y personal en materia de asesoramiento. En cuanto al factor extrínseco y analizando los datos, apuntamos a una falta de apoyo institucional debido a que en diversas ocasiones existen procesos aislados de mentoría a docentes noveles con carácter informal, sin determinar si el mentor está capacitado o no profesionalmente para ello. Por último, destacamos que todos los participantes son los primeros mentores nombrados en República Dominicana, hecho que les hace sentir orgullosos de poder avanzar en la calidad educativa de su país y ser promotores del cambio.

\section{CONCLUSIONES}

En la síntesis de los resultados presentados destacamos que las conclusiones mostradas, a continuación, dan respuesta a las necesidades formativas y profesionales de los profesores mentores principiantes atendiendo al objetivo general del estudio (conocer y analizar el desarrollo profesional docente en el mentor principiante, teniendo en cuenta antecedentes formativos/profesionales y por consiguiente, posibles obstáculos y necesidades formativas/ profesionales surgidos durante el periodo de mentoría). En la primera de las cuestiones de investigación, ¿cuáles son los antecedentes formativos y laborales del mentor principiante? matizamos que éstos van en la línea de la diversidad de trayectorias formativas y profesionales ligadas a la educación. Por lo que las necesidades formativas van en el camino de la mejora continua, convirtiéndose la formación permanente, primordial para desarrollar las funciones de mentoría teniendo un bagaje anterior en materia de educación con diversas carreras y especialidades. Atendiendo a Wong (2005) en su investigación apuntamos que para mantener una buena interacción con el docente principiante es necesaria una formación para avanzar en el desarrollo profesional, la instrucción y la evaluación, es necesaria una formación sobre cómo entrenar las competencias del mentor a lo largo de 40 horas presenciales. Siguiendo al mismo autor en otra de sus investigaciones encontramos que en las escuelas de Georgia se trabaja la formación de los mentores en 100 horas presenciales. En nuestro caso, la formación permanente de los mentores ha sido desarrollada a lo largo de tres sesiones presenciales en República Dominicana y a distancia a través de una plataforma. Otro de los estudios relevantes y actuales es "Mutual Mentoring" de los autores Yun, Baldi, y Sorcinelli (2016) atendiendo a la mentoría de manera conjunta como un nuevo modelo de asesoramiento y tutoría para apoyar a los futuros profesores desde antes de acabar sus estudios universitarios. Aun así, en la evolución formativa de los mentores detectamos carencias formativas tecnopedagógicas, por lo que se hace necesaria esta formación para desarrollar las funciones de asesoramiento como mentores y convirtiéndose en la práctica en obstáculos a superar. Los conflictos en el aula juegan un papel importante en el desarrollo profesional de los docentes principiantes y por ende en la formación impartida por los mentores principiantes teniéndoles que dotar de recursos y técnicas para su mejora en el día a día en el aula. Esto conlleva a otro obstáculo presente de tipo tecnológico ya que la indagación de nuevas técnicas la realizan los mentores principiantes y necesitan entrenamiento en el uso de las nuevas tecnologías. 
La siguiente cuestión de investigación está relacionada con el tiempo de dedicación a la mentoría y las carencias laborales, ¿qué necesidades profesionales encuentra el profesor mentor principiante en la práctica? Para dar cabida a la respuesta de esta pregunta destacamos que las necesidades profesionales están íntimamente ligadas al factor tiempo, el que determina la puesta en práctica de las funciones del mentor. Es por esto que ante los resultados obtenidos, los profesores mentores principiantes, necesitan tener más horas libres para desarrollar el rol, ante la ocupación en otros cargos laborales. Uno de los puntos de selección de los mentores es liberar al mentor de cualquier otra ocupación laboral y en la mayoría de los casos, en la práctica, no ha sido así. En la narración de los incidentes críticos se hace latente este problema de investigación, la falta de tiempo para las visitas a los docentes principiantes ya que los centros educativos asignados pertenecen a la misma regional donde viven, pero a largas distancias unos de otros. Esto conlleva a poder visitar solo un centro y docente principiante por día lo que dificulta el aprovechamiento del escaso tiempo para el asesoramiento. Los autores Hudson, Hudson, Gray y Bloxham (2013), señalan que los mentores efectivos son comunicadores que voluntariamente comparten el conocimiento y los recursos para mejorar la enseñanza y el aprendizaje con un tiempo establecido para ello. También indicaron que una relación positiva entre el mentor y el aprendiz con respeto mutuo aparece en el centro del proceso de mentoría y se convierte en un conducto para discutir las prácticas pedagógicas. (p. 1298)

Y la última de las cuestiones a responder es ¿qué obstáculos encuentran en sus trayectorias profesionales y formativas para desempeñar el rol de mentor? Anteriormente hemos mostrado obstáculos como son el tiempo y la formación permanente, pero continuamos, en base a lo anterior, destacando el apoyo institucional. Apuntamos que es clave para la mejora ya que existe una falta latente de soporte de tipo institucional-gubernamental con carácter formal tanto para los programas de iniciación a la práctica profesional como para paliar la diversidad de obstáculos en el camino de la mentoría. Realmente al ser una figura nueva en el contexto educativo necesita más apoyo para poder afianzarla. Se dan procesos en la práctica como la falta de empatía de órganos directivos de los centros, con falta de apoyo y dudas en cuanto al desempeño profesional. En estos casos comunes los mentores tienen que mediar entre ambas figuras para que se comience a confiar en el desarrollo profesional y personal tanto de los docentes principiantes como de la propia figura del mentor.

En tal punto reconocemos limitaciones en cuanto a la revisión bibliográfica específica en mentoría, accesibilidad presencial a los participantes y factores temporales debido al cambio horario entre República Dominicana y España. A pesar de todo ello enfatizamos que los participantes se sienten inspiradores de la transformación de la educación hacia la mejora de la calidad educativa de República Dominicana desde las aulas universitarias (algunos mentores comparten el rol con el de docente universitario) formando a los futuros docentes, hasta las aulas de educación básica, inicial y media asesorando a los docentes principiantes.

Las futuras implicaciones de esta investigación versan sobre el entrenamiento en obstáculos y necesidades antes, durante y después de la mentoría con la finalidad de que el profesor mentor principiante actual se convierta en profesor mentor experto que forme a los nuevos roles. Ante ello, sería primordial un apoyo institucional para crear la figura del mentor como un cargo educativo oficial en las escuelas de República Dominicana.

A su vez, esta investigación, puede avanzar en materia tecno-pedagógica para dar soporte continuo a los profesores mentores principiantes con la finalidad de convertirles en formador de formadores, es decir, los mentores expertos asesoran al mentor principiante. 
Por lo que la investigación puede llegar a englobar la mentoría en países latinoamericanos desde el rol de mentores digitales para poder avanzar en clave de mejora educativa.

Otra de las futuras líneas de esta investigación puede ser un estudio longitudinal en torno a 5 años para comprobar el estado actual formativo de los profesores mentores expertos y analizar la formación dada a los profesores mentores noveles. Del mismo modo se puede plantear la hipótesis de investigación a largo plazo para detectar si los nuevos profesores mentores cuentan con menor o mayor formación tecno-pedagógica en materia de educación que los profesores mentores expertos.

\section{REFERENCIAS BIBLIOGRÁFICAS}

Abrahão, M. H. \& Bolívar, A. (2014). La investigación auto biográfica en educación. Miradas cruzadas entre Brasil y España. Granada y Porto Alegre: EDIPUCRS.

Beca, C. E. (2012). Informe final de consultoría sobre políticas docentes en República Dominicana. Santiago de Chile: OEI.

Calderón, J. (coord.). (2020). Acompañamiento pedagógico: docentes noveles de Chile, Ecuador, México y Uruguay. Zacateca, México: Universidad Pedagógica Nacional Unidad Zacatecas.

Castro, M.A. \& Castro, L. (2001). Cuestiones de metodología cualitativa. EMPIRIA. Revista de Metodología de Ciencias Sociales, 4, 165-190.

Crisp, G. \& Cruz, I. (2009). Mentoring college students: A critical review of the literature between 1990 and 2007. Research in higher education, 50(6), 525-545.

Domingo, J. \& Fernández, M. (1999). Técnicas para el desarrollo personal y formación del profesorado. Bilbao: Universidad de Deusto.

Escudero, J. M., González, M. T. \& Rodríguez, M. J. (2018). Los contenidos de la formación continuada del profesorado: ¿qué docentes se están formando? Educación XX1, 21(1), 157-180.

Fernández-Salinero, C., Belando, M. R. \& González, M. R. (2017). Mentoría pedagógica para profesorado universitario novel: estado de la cuestión y análisis de buenas prácticas. Estudios Sobre Educación, 33, 49-75.

Fogarty, T., Reinstein, A., Heat, R. \& Sinason, D. (2017). Why mentoring does not always reduce turnover: The intervening roles of value congruence, organizational knowledge and supervisory satisfaction. Advanced in accounting, 38(C), 63-74.

Gewerc, A. \& Montero, L. (2015). Conocimiento profesional y competencia digital en la formación del profesorado. El caso del Grado de Maestro en Educación Primaria. RELATEC: Revista Latinoamericana de Tecnología Educativa, 14(1), 32-43.

González, J. F., Pérez, M. M. \& Escartín, N. E. (2003). Enseñar a profesores de secundaria con situaciones problemáticas. Revista Electrónica de Enseñanza de las Ciencias, 2(3), 263-270.

Gunuc, S. \& Kuzu, A. (2015). Student engagement scale: development, reliability and validity. Assessment \& Evaluation in Higher Education, 40(4), 587-610.

Hennink, M., Hutter, I. \& Bailey, A. (2011). Qualitative research methods. London: Sage.

Hernández, E. (2013). El diálogo con las historias de vida: la narrativa de los incidentes críticos en la trayectoria vital de jóvenes. Revista de Educación Inclusiva, 6(1), 90-106.

Herrera, L., Fernández, A. M., Caballero, K. \& Trujillo, J. M. (2011). Competencias docentes del profesorado novel participante en un proyecto de mentorización. Implicaciones para el desarrollo profesional universitario. Profesorado, Revista de Currículum y Formación del Profesorado, 15(3), 213-241.

Hudson, P., Hudson, S., Gray, B. \& Bloxham, R. (2013). Learning about being effective mentors: Professional learning communities and mentoring. Procedia-Social and Behavioral Sciences, 93, 1291-1300. 
IDEICE. (2014). Evaluación de impacto del coordinador docente en los centros educativos de República Dominicana. Santo Domingo: MINERD.

Lindén, J., Ohlin, M. \& Brodin, E. M. (2013). Mentorship, supervision and learning experience in PhD education. Studies in Higher Education, 38(5), 639-662.

López, Y. (2015). La autobiografía (de) constructora del que-hacer-se educativo. Tropelias: Revista de teoría de la literatura y literatura comparada, (23), 73-89.

Marcelo, C. (2002). Aprender a enseñar en la sociedad del conocimiento. Revista Complutense de Educación, 12(2), 531-593.

Marchesi, A. (2007). Sobre el bienestar de los docentes. Competencias, emociones y valores. Madrid: Alianza Editorial.

Martín-Romera, A. \& García-Martínez, I. (2018). Profesionalización del docente en la actualidad: Contribuciones al desarrollo profesional. Profesorado: Revista de curriculum y formación del profesorado, 22(1), 7-23.

Martínez, N. H. (coord.). (2012). Alzando el vuelo. Problemas y modelos de asesoramiento al docente novel. México: Fondo Editorial de NL.

Martínez, C.A. \& Valbuena, E. O. (2013). Complejidad del conocimiento profesional de una profesora de ciencias de Primaria sobre el conocimiento escolar. Campo Abierto, 32(1), 117-135.

Miles, M. B. \& Huberman, A. M. (1994). Qualitative data analysis: An expanded sourcebook (2nd ed.). Thousand Oaks, CA: Sage.

Montecinos, C. (2003). Desarrollo profesional docente y aprendizaje colectivo. Psicoperspectivas, 2(1), 105-128.

Núñez, D. E. (2019). Teorías implícitas: su naturaleza contextual y práctica como saber docente profesional. Qurriculum, 32, 213-223.

Núñez, C. G., Pino, M. \& López, V. (2011). Horizontes de posibilidad de la mentoría en Chile: Análisis de la experiencia piloto desde la perspectiva del discurso. Educação \& Sociedade, 32(117).

Organización para la Cooperación y el Desarrollo Económico (OECD). (2017). ¿Cómo puede el desarrollo profesional mejorar las prácticas docentes en el aula? Teaching in Focus, (16), 1-5.

Rikard, G. L. \& Banville, D. (2010). Effective mentoring: Critical to the professional development of first year physical educators. Journal of Teaching in Physical Education, 29(3), 245-261.

Por, P. \& Ramírez, N. (2004). Situación de la Educación Rural en la República Dominicana. Situación, 13(16), 19.

Secretaría de Estado de Educación. (2009). Plan Decenal de Educación 2008-2018. Construyendo la respuesta nacional para lograr la Educación Dominicana de Calidad que queremos. Santo Domingo, República Dominicana: SEE.

Vaillant,D. (2007). Mejorandola formación y el desarrollo profesional docente enLatinoamérica. Revista Pensamiento Educativo, 41(2), 207-222.

(2016). El fortalecimiento del desarrollo profesional docente: Una mirada desde Latinoamérica. Journal of Supranational Policies of Education, 5, 5-21. Recuperado de http:// dx.doi.org/10.15366/jospoe2016.5.

Vaillant, D. \& Marcelo, C. (2015). El A, B, C y D de la formación docente. Madrid: Narcea.

Vaillant, D. \& Cardozo-Gaibisso, L. (2016). Desarrollo profesional docente: entre la proliferación conceptual y la escasa incidencia en la práctica de aula. Cuaderno de Pedagogía Universitaria, 13(26), 5-14.

Vezub, L. (2011). Las políticas de acompañamiento pedagógico como estrategia de desarrollo profesional docente. El caso de los programas de mentoría a docentes principiantes. Revista del IICE, (30), 103-124.

Wong, H. K. (2005). New Teacher Induction. Teacher Mentoring and Induction, 3, 41-58.

Yun, J. H., Baldi, B. \& Sorcinelli, M. D. (2016). Mutual mentoring for early-career and underrepresented faculty: Model, research, and practice. Innovative Higher Education, 41(5), 441-451. 